\title{
Treatment of hypogammaglobulinaemia with intravenous immunoglobulin, 1973-93
}

\author{
Susan Skull, Andrew Kemp
}

\begin{abstract}
Aims-To review the results of long term high dose intravenous immunoglobulin treatment.

Methods-162 treatment years in $18 \mathrm{pa}-$ tients with hypogammaglobulinaemia who received intravenous immunoglobulin treatment between 1973 and 1993 were reviewed.

Results-A mean dose of $0.42 \mathrm{~g} / \mathrm{kg}$ immunoglobulin resulted in a mean trough IgG concentration on the 23.5th centile for age. The subjects enjoyed a good standard of health. Infection rates were similar to the general paediatric population and a similar pattern of infections occurred. There were only 0.06 episodes of pneumonia and 0.11 hospital admissions per year of treatment. The development of chronic pulmonary disease was significantly related to trough IgG concentrations less than the 10th centile $(p<0.009)$, however, this developed in only two children after the start of treatment. All children had normal growth parameters. Adverse reactions to immunoglobulin infusions reduced from $9.1 \%$ to $0.8 \%$ after the introduction of low pH modified intravenous immunoglobulin in 1986. Although minor, transient increases in liver transaminase values were common; none of the 11 patients tested by hepatitis $\mathrm{C}$ polymerase chain reaction were positive.

Conclusion-Children with hypogammaglobulinaemia who are receiving replacement treatment grow normally and have an infection rate similar to that of nonimmunodeficient children. No evidence of transmission of hepatitis $C$ virus by the Commonwealth Serum Laboratories immunoglobulin was found. (Arch Dis Child 1996;74:527-530)
\end{abstract}

Keywords: intravenous immunoglobulin, hypogammaglobulinaemia.

Department of Immunology, Royal Children's Hospital Melbourne, Australia S Skull

A Kemp

Correspondence to: $\operatorname{Dr} A$ Kemp, Department of Immunology, Royal

Children's Hospital

Flemington Road, Parkville, Victoria, 3052

Australia.

Accepted 22 February 1996 report the long term results of immunoglobulin treatment in hypogammaglobulinaemia Sweinberg et al reported 21 adults and children followed up for a total of 251 treatment years with intramuscular therapy, ${ }^{5}$ and Liese et al described 24 children treated with intravenous therapy for a total of 101 treatment years. ${ }^{6}$ However only 50 of these treatment years were with high dose $(300-600 \mathrm{mg} / \mathrm{kg}$ ) immunoglobulin replacement. We describe the results of high dose intravenous immunoglobulin treatment in 18 children with hypogammaglobulinaemia treated for 162 treatment years.

\section{Patients and methods}

PATIENTS

Eighteen children (15 boys, three girls) with antibody deficiency treated at the Royal Children's Hospital, Melbourne, Australia between April 1973 and November 1993 were included. The antibody deficiencies were $\mathrm{X}$ linked agammaglobulinaemia (XLA, 10 boys), hyper-IgM syndrome (three boys), common variable immunodeficiency (CVID, two boys,

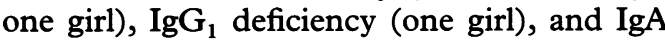
combined $\mathrm{IgG}_{2}$ deficiency (one girl). Five children were transferred to adult hospitals during this period and data were collected for these patients until treatment ceased at the Royal Children's Hospital. The median age at diagnosis was 1.1 years (range 0.2-9.1 years) and the median patient age when reviewed was 11.8 years (range $1.25-22.25$ years).

\section{IMMUNOGLOBULINS}

Intravenous immunoglobulin was manufactured by Commonwealth Serum Laboratories (CSL), Melbourne, Australia as a $6 \%$ solution prepared by ethanol fractionation. From 1974 until June 1986 patients received 'standard' CSL, normal human immunoglobulin at $\mathrm{pH}$ 6.5 which did not contain maltose. From June 1986 a 'modified' preparation at $\mathrm{pH} 4.0$ plus $10 \%$ maltose was used. Since May 1990 an immunoglobulin was prepared from plasma pools free of hepatitis $\mathrm{C}$ virus antibody. ${ }^{7}$

IMMUNOGLOBULIN ADMINISTRATION

Immunoglobulin was administered intravenously monthly at a day clinic. Exceptions were two children who received some infusions in country centres and one child received home infusions intermittently. Seventeen of $18 \mathrm{pa}-$ tients received monthly immunoglobulin; one girl with IgA and IgG $_{2}$ deficiency received intermittent treatment. Five patients had initial intramuscular immunoglobulin before starting intravenous treatment, receiving a median number of 15 injections (range 6-42). Thirteen patients received intravenous treatment 
Table 1 Infection rates during immunoglobin treatment

\begin{tabular}{|c|c|c|c|c|c|}
\hline \multirow[t]{2}{*}{ Type of infection } & \multicolumn{5}{|c|}{ No of infections/patient year of treatment } \\
\hline & Actual no & Mean & Median & Range & Normal mean * \\
\hline Respiratory & 539 & 3.33 & 3.17 & $1.03-6.77$ & 4.8 \\
\hline $\begin{array}{l}\text { Skin }+ \text { mucous } \\
\text { membrane }\end{array}$ & 118 & 0.73 & 0.56 & $0.00-1.50$ & \\
\hline Gastrointestinal & 103 & 0.64 & 0.55 & $0.00-2.83$ & 0.9 \\
\hline Fever only & 8 & 0.02 & 0 & $0.00-0.08$ & total \\
\hline Dental abscess & 4 & 0.03 & 0 & $0.00-0.22$ & \\
\hline Total & 772 & 4.79 & 4.33 & $1.34-9.17$ & 5.6 \\
\hline
\end{tabular}

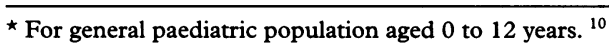

only, and after 1977 all patients received intravenous immunoglobulin. The median age at the start of treatment was 1.1 years (range $0.2-$ 9.1 years). The median number of 'patient years of treatment' with immunoglobulin was 7.9 years (range $1.1-17.8$ years). The median number of intravenous infusions was 100 (range 15-188).

ADVERSE REACTIONS

Adverse reactions were classified as immediate or delayed. Immediate reactions occurred during immunoglobulin infusion and were graded on a scale from 0 to $5: 0$, no reaction; 1 , minor reaction not requiring intervention; 2 , minor reaction requiring symptomatic treatment; 3 , moderate reaction requiring slowing of infusion rate; 4 , moderate reaction requiring interruption of infusion; 5 , marked reaction requiring interruption of infusion and administration of IV methylprednisolone. ${ }^{8}$ Delayed reactions were defined as symptoms (headache, abdominal pain, nausea or vomiting, fever) starting within 24 hours of the infusion.

\section{INVESTIGATIONS}

Trough serum IgG was measured before each infusion and recorded as an age dependent centile, allowing comparison between different ages. ${ }^{9}$ From August 1986 serum aspartate aminotransferase (AST) was measured before each infusion, and was considered abnormal if above the upper limit of the reference range for age ( $<1$ year, 20-80 IU/1; $1-3$ years, $15-60$ IU/1; and 3-16 years, 10-45 IU/1) on more than one occasion. Polymerase chain reaction analysis of serum for detection of hepatitis $C$ virus was performed in 11 subjects. Chest radiographs were taken at diagnosis and thereafter annually or with suspected infection, and were interpreted by a radiologist. Pulmonary function tests were recorded in 13 children starting from a mean age of 11.3 years.

\section{GROWTH}

Growth was assessed from the most recent height and weight recordings available. Using World Health Organisation 1983 guidelines, weight for height was considered the most appropriate measure of nutritional status for males up to $145.0 \mathrm{~cm}$ and females up to 137.0 $\mathrm{cm}$. This applied to nine of 17 children. Height for age was used as an indicator of stunting in all children.

\section{ILLNESS}

Infections and antibiotic use reported by patients at the time of intravenous treatment were recorded. Children were seen every four weeks and inquiry into previous infections was a routine part of each visit. Infections were subdivided into: respiratory (including ear, nose, and throat infections); skin and mucous membrane; gastrointestinal tract; fever alone; and dental abscess. The number of hospital admissions and days in hospital were also recorded.

\section{Results}

\section{DOSE AND SERUM CONCENTRATION OF}

IMMUNOGLOBULIN

The dose administered in June of each year was used to determine a mean overall dose for each child. The median intravenous immunoglobulin dose for all years of treatment was $0.41 \mathrm{~g} / \mathrm{kg}$ (mean $0.42 / \mathrm{kg}$; range $0.27-0.59 \mathrm{~g} / \mathrm{kg}$ ). This provided median trough IgG concentrations on the 17.6th centile for age (mean 23.5th centile).

\section{GROWTH}

One child with short stature considered to be syndromal was excluded from this analysis. Growth parameters for all other children were within normal limits. The median weight at the completion of study was 50th centile for age (range 3rd-97th) and the median height was 25 th centile (range $3 \mathrm{rd}-97 \mathrm{th}$ ). The mean weight for height ratio was on the 52 nd centile and mean height for age on the 38 th centile.

\section{INFECTIONS}

The median total number of infections recorded per patient year of treatment was 4.33 . The most common site of infection was the respiratory tract. Central nervous system infection did not occur in this study. For comparison, the number of infections for normal Australian children calculated from the data of Roberton and Hosking are shown (table 1). ${ }^{10}$

\section{HOSPITAL ADMISSIONS}

Eighteen of 772 infections (2.3\%) required hospitalisation over a treatment period of 162 years (mean 0.11 admissions per patient year of treatment; median 0; range 0-0.32). These admissions occurred in seven patients. The mean length of hospital stay was 5.67 days (range 0-26). Lower respiratory infection accounted for $72 \%$ of admissions (pneumonia nine, bronchitis two, croup two). Other admissions were for gastroenteritis (two), noninfective mouth ulcers (one), and fever of unknown origin (one).

\section{ANTIBIOTIC USE}

The mean number of antibiotic courses recorded per patient year of treatment was 3.71. This included six children who at some time received antibiotic prophylaxis as daily administration of low dose co-trimoxazole or amoxycillin to prevent bacterial infection. The mean duration of use for these children was 16 months (range 6-36 months). When prophylactic antibiotic courses were excluded, the mean number of antibiotic courses taken per patient year of treatment was 3.09. 
Table 2 Adverse reactions before and after introduction of modified immunoglobin

\begin{tabular}{llllllllll}
\hline Time period & $\begin{array}{l}\text { Reactions/intravenous } \\
\text { infusion }\end{array}$ & \multicolumn{3}{l}{ Immediate reactions (grade) } & \multicolumn{2}{c}{$\begin{array}{l}\text { Delayed } \\
\text { reactions }\end{array}$} \\
\cline { 3 - 8 } & & Total 1 & 2 & 3 & 4 & 5 & \\
\hline Jan 1973-Jun 1986 & $61 / 667(9.1 \%)$ & 59 & 17 & 25 & 15 & 2 & 0 & 2 \\
Jul 1986-Nov 1993 & $11 / 1400(0.8 \%)$ & 9 & 2 & 6 & 0 & 1 & 0 & 2 \\
\hline
\end{tabular}

Table 3 Abnormal AST measurements before and after hepatitis $C$ antibody screening of donor pools

\begin{tabular}{lll}
\hline & Aug 1986-April 1990 & May 1990-Nov 1993 \\
\hline $\begin{array}{l}\text { No of patients with abnormal AST > } \\
\text { occasion }\end{array}$ & $8 / 16(50 \%)$ & $6 / 18$ (33\%) \\
Total No of AST measurements & 552 & 576 \\
Median value for abnormal AST & 54.5 & 51.0 \\
Mean value for abnormal AST & 59.7 & 57.2 \\
Maximum value for abnormal AST & 153 & 213
\end{tabular}

CHEST RADIOGRAPHY AND PULMONARY

FUNCTION TEST ABNORMALITIES

Three of 18 patients had persistent changes on chest radiography consistent with bronchiectasis: one with XIA, one with CVID, and one with IgG $_{1}$ deficiency. This latter patient had syndromal short stature and radiographic changes of bronchiectasis at the start of treatment at 9 years of age. There was a significant association between bronchiectasis and trough IgG concentrations: all three patients with bronchiectasis had IgG trough values less than the 10 th centile (mean 6 th centile), compared with a mean of the 27 th centile for those without bronchiectasis ( $p<0.009$ using Wilcoxon rank sum test). Thirteen of 18 children had pulmonary function tests performed. All were normal except the child with IgG deficiency who had a restrictive pattern on diagnosis at 9 years. The mean forced expiratory volume in one second was $107.9 \%$ of predicted value for height (range 70-139\%, median $110 \%$ ). The mean forced vital capacity was $105.0 \%$ of predicted value for height (range 73-125\%, median 106\%).

ADVERSE REACTIONS

Nine subjects suffered 72 adverse reactions in 2067 intravenous immunoglobulin infusions (mean 0.03 reactions per infusion) (table 2). The majority were immediate reactions of a minor nature (grades 1 and 2) (table 2). A marked decrease in reactions from June 1986 was observed after modification of the immunoglobulin preparation by treatment at $\mathrm{pH} 4.0$.

LIVER FUNCTION TESTS

From 1986 AST measurements were monitored monthly in view of the potential transmission of non-A, non-B hepatitis. After May 1990 donors with hepatitis $C$ antibodies were excluded from the donor pool. Transient increases in AST measurements were common before and after this time (table 3). Of the eight patients with abnormal AST measurements before May 1990, five had abnormal ASTs after 1990. One patient who had previously normal AST measurements before May 1990 developed abnormal ASTs after 1990. Eleven patients had hepatitis $C$ virus polymerase chain reaction assays performed on serum in Novem- ber 1993 and all were negative. This included the six who had abnormal AST values after May 1990.

\section{Discussion}

This study of 18 patients treated for 162 treatment years comprises one of the largest reported patient years of treatment with high dose intravenous immunoglobulin. Liese et al described 12 subjects treated with high dose intravenous immunoglobulin for 50 treatment years. ${ }^{6}$ The incidence of pneumonia $(0.05$ episodes per year of treatment) was similar to that of Liese et al (0.03 episodes per year of treatment) and one third that observed by Sweinberg et al (0.14 episodes per year of treatment) ${ }^{5}$ in subjects treated with intramuscular immunoglobulin. The days of hospitalisation ( 0.6 per year of treatment) was the same as that reported by Liese et al. This study documents the good state of health that can be expected by children with antibody deficiency when maintained on high dose intravenous treatment. Growth, infection rate, hospital admissions, and antibiotic use were chosen as measures of patient wellbeing. There are very few references to the growth of subjects receiving replacement immunoglobulin treatment. ${ }^{511}$ All of our patients had normal growth parameters. The infection rate in our children appeared to be similar to the general paediatric population. ${ }^{10} \mathrm{~A}$ possible contributing factor is that immunoglobulin treatment prevents or ameliorates some of the common viral infections in childhood. Severe infections, requiring hospitalisation, were uncommon and most often due to lower respiratory tract infection. The use of antibiotics ( 3.7 courses per year of treatment) was similar to that of nonimmunodeficient children. Thus, the mean number of antibiotic courses prescribed per head of the Australian population per year was 1.19 for the financial year 1992-3, considering eight of the most commonly used antibiotics in childhood. ${ }^{12}$ The antibiotic prescription rate by general practitioners for children aged 1-14 is 2.6 times that of adults aged $45-64^{13}$ indicating approximately three antibiotic prescriptions per child per year for the general population.

Chronic pulmonary disease is the most common long term complication in patients with hypogammaglobulinaemia. ${ }^{14}$ Only one of 13 patients $(8 \%)$ had an abnormal pulmonary function test, a finding comparable with that of Liese et al who found one of nine children on high dose treatment had an abnormal test. ${ }^{6}$ This contrasts with the results of Swienberg $e t$ al where $13 / 22$ (59\%) of subjects maintained on intramuscular immunoglobulin had an abnormal pulmonary function test. ${ }^{5}$ Spirometric evidence of obstructive lung disease, reported to be the most common abnormality seen in subjects with hypogammaglobulinaemia, ${ }^{5}$ was not seen in any of our subjects. One child had radiographic evidence of bronchiectasis before institution of treatment and two developed permanent radiological changes indicative of bronchiectasis. This may be contrasted with findings in a group of eight 
boys with agammaglobulinaemia treated at our institution from 1958 to 1972 with intramuscular therapy where on review all had permanent radiological abnormalities on chest radiography. ${ }^{15}$

With the current $\mathrm{pH}$ modified intravenous immunoglobulin preparations there are few complications of treatment. Until June 1986, the rate of reactions to intravenous immunoglobulin at our institution was $9.1 \%$, despite measures such as prophylactic methylprednisolone. ${ }^{16}$ At this time a modified human immunoglobulin at low $\mathrm{pH}(4.0)$ containing $10 \%$ maltose was introduced and the reaction rate dropped to $0.8 \%{ }^{8}$ We further document that the low $\mathrm{pH}$ treatment of immunoglobulins markedly reduces the adverse reaction rate.

Another cause for concern with intravenous immunoglobulin is the transmission of non-A, non-B hepatitis. ${ }^{17-20}$ Since May 1990, all immunoglobulin used in Australia has been produced from fractionation pools screened for hepatitis $\mathrm{C}$ virus antibody. ${ }^{7} \mathrm{It}$ is recommended practice to monitor serum transaminases as an indicator for developing hepatitis, ${ }^{21}$ however the interpretation of values outside the normal range remains uncertain. Transient minor increases in transaminases (AST $<100 \mathrm{IU} / \mathrm{l}$ ) have been observed in a substantial number of hypogammaglobulinaemic patients receiving intravenous immunoglobulin in whom liver function is regularly assessed. ${ }^{7} 22$ Whether this indicates subclinical hepatitis $C$ is unknown. Taliani et al recently reported that one of 14 patients maintained on second generation immunoglobulin for a mean of 7.6 treatment years was positive for hepatitis C virus by polymerase chain reaction testing. ${ }^{20}$ All 11 hepatitis $C$ virus polymerase chain reaction tests performed in our study were negative and of these seven children had minor increases in AST (94\% of these raised results being below $100 \mathrm{IU} / 1)$. We conclude that there is no evidence of transmission of hepatitis C virus by the CSL immunoglobulin preparation. The use of routine AST monitoring appears to have little value and yearly testing for hepatitis $\mathrm{C}$ virus by the polymerase chain reaction may be more useful.

1 Eibl MM, Cairns L, Rosen FS. Safety and efficacy of a monomeric, functionally intact intravenous IgG preparation in patients with primary immunodeficiency syndromes. Clin Immunol Immunopathol 1984; 31: 151-60.
2 Ugazio AG, Duse $M$, Notarangelo LD. Intravenous immunoglobulin and immunodeficiency in children. Current Opinion in Pediatrics 1989; 1: 5-12.

3 Huston DP, Kavanaugh AF, Rohane PW, Huston MM. Immunoglobulin deficiency syndromes and therapy. $f$ Allergy Clin Immunol 1991; 87: 1-16.

4 Roberton DM, Hosking CS. The long term treatment of childhood hypogammaglobulinaemia in Melbourne with intravenous gammaglobulin,1972-1985. Dev Biol Stand 1987; 67: 273-80.

5 Sweinberg SK, Wodell RA, Grodofsky MP, Greene JM, Conley ME. Retrospective analysis of the incidence of pulmonary disease in hypogammaglobulinemia. $\mathcal{F}$ Allergy Clin Immunol 1991; 88: 96-104.

6 Liese JG, Wintergest U, Tympner KD, Belohradsky BH. High vs low-dose immunoglobulin therapy in the long High vs low-dose immunoglobulin therapy in the long Dis Child 1992; 146: 335-9.

7 Schiff P, Kemp A. Safety of IVIG made from HCVantibody-screened plasma. Lancet 1991; 338: 1076.

8 Roberton DM, Hosking CS, Efthimiou H, Wright S. Decreased incidence of adverse reactions in hypogammaglobulinemic children receiving low $\mathrm{pH}$ intravenous immunoglobulin. Aust N Z F Med 1987; 17: 495-500.

9 Shelton MJ, Meek F, Goller I, Hosking CS. Serum immunoglobulin levels in children. Australian fournal of Medical Technology 1974; 5: 113-7.

10 Roberton DM, Hosking CS. Childhood infections: why and how many? In: Buchanan, ed. Child and adolescent health for practitioners. Sydney:Williams and Williams, 1987: 205-27.

11 Roifman CM, Lederman HM, Lavi G, Stein LD, Levison $\mathrm{H}$, Gelfand EW. Benefit of intravenous IgG replacement in hypogammaglobulinemic patients with chronic sinopulmonary disease. $A m$ f Med 1985; 79: 171-4.

12 Drug Utilisation Sub-Committee, Pharmaceutical Benefits Advisory Committee. Antibiotic drugs, PBS full count and guild estimates,prescription totals by quarter during 1991 1993. Canberra, Australia: Drug Utilisation Subtee, 1994 .

13 Britt H, Miles DA, Neary S, Charles J, Traynor V, BridgesWebb C. Morbiditiy and treatment in general practice in Australia 1990-1991. Med f Aust 1992; 157: S1-57.

14 Lederman HM, Winkelstein JA. X-linked agammaglobulinemia: an analysis of 96 patients. Medicine 1985; 64: 145-56.

15 Phelan PD, Landau LI, Williams HE. Lung disease associated with infantile agammaglobulinaemia. Aust Paediatr f 1973; 9: 147-51.

16 Roberton DM, Hosking CS. Use of methylprednisolone as prophylaxis for immediate adverse infusion reactions in hypogammaglobulinaemic patients receiving intravenous immunoglobulin: a controlled trial. Aust Paediatr $\mathcal{F} 1988$; 24: 174-7.

17 Lever AML, Webster ADB, Brown D, Thomas HC. Non-A, non-B hepatitis occurring in agammaglobulinaemic patients after intravenous immunoglobulin. Lancet 1984; i: tients after

18 Williams PE, Yap PL, Gillon J, Crawford RL, Urbaniak SJ, Galea $G$. Transmission of non-A, non-B hepatitis by $\mathrm{pH} 4$ treated intravenous immunoglobulin. Vox Sang 1989; 57: 15-8.

19 Weiland O, Maltson L, Glaumann H. Non-A, non-B hepatitis after intravenous gammaglobulin. Lancet 1986; i: 976-7.

20 Taliani G, Guerra E, Rosso R, et al. Hepatitis C virus infection in hypogammaglobulinemic patients receiving longtion in hypogammaglobulinemic patients receiving longterm replacement therapy with in
bulin. Transfusion 1995; 35: 103-7.

21 Chapel HM. Consensus panel for the diagnosis and management of primary antibody deficiencies. Consensus on diagnosis and management of primary antibody deficiencies. $B M F$ 1994; 308: 581-5.

22 Hany M, Ryan A, Webster ADB. Long term safety and tolerability of intravenous immunoglobulin. Lancet 1991; 335: 1274-5. 